\title{
Supply chain network design problem for a new market opportunity in an agile manufacturing system
}

\author{
Reza Babazadeh, Jafar Razmi and Reza Ghodsi
}

\begin{abstract}
The characteristics of today's competitive environment, such as the speed with which products are designed, manufactured, and distributed, and the need for higher responsiveness and lower operational cost, are forcing companies to search for innovative ways to do business. The concept of agile manufacturing has been proposed in response to these challenges for companies. This paper copes with the strategic and tactical level decisions in agile supply chain network design. An efficient mixed-integer linear programming model that is able to consider the key characteristics of agile supply chain such as direct shipments, outsourcing, different transportation modes, discount, alliance (process and information integration) between opened facilities, and maximum waiting time of customers for deliveries is developed. In addition, in the proposed model, the capacity of facilities is determined as decision variables, which are often assumed to be fixed. Computational results illustrate that the proposed model can be applied as a power tool in agile supply chain network design as well as in the integration of strategic decisions with tactical decisions.
\end{abstract}

Keywords: Supply chain management, Agile supply chain network design, Outsourcing, Responsiveness

\section{Background}

In recent years, the design and implementation of agile supply chain strategies have increasingly attracted interest and some companies such as Zara and Gina Tricot have achieved many advantages by employing agile strategy. Agile supply chain includes companies such as suppliers, production centers, and distribution centers, which are legally separate but, in terms of operations, are linked together by forward-flow materials and feedback information. Agile supply chain is focused on improving responsiveness, speed, and flexibility that is able to respond and react quickly and effectively to changing markets (Lin et al. 2006). In other words, agility is a term applied to an organization that has created the processes, tools, and training to enable it to respond quickly to customer needs and unforeseen market changes while still controlling costs and quality (Christopher et al. 2004). Traditional supply chains have long lead times

\footnotetext{
* Correspondence: jrazmi@ut.ac.ir

Department of Industrial Engineering, College of Engineering, University of
}

(c) 2012 Babazadeh et al.; licensee Springer. This is an Open Access article distributed under the terms of the Creative Commons Attribution License (http://creativecommons.org/licenses/by/2.0), which permits unrestricted use, distribution, and reproduction in any medium, provided the original work is properly cited. inventory-based, while the agile supply chain with quick response has shorter lead time and is demand-driven and information-based, in contrast with traditional supply chains. Additionally, while the market winning factor in agile supply chain is responsiveness and improved service level, in traditional supply chain, cost has been the market winning factor (Mason-Jones et al. 2000). Agile supply chain practices can be identified by four factors (Harrison et al. 1999):

1. Market sensitive. It is concerned with end customers in order to be able to specify customer needs and responds to them as soon as possible.

2. Virtual integration. It depends on information sharing along the supply chain.

3. Network-based. It provides flexibility by employing the strengths of specialism in each partner within the supply chain; therefore, it is critical to leverage the strengths and competencies of partners to realize quick responsiveness to market needs.

\section{Department of Industrial Engineering,
Tehran, Tehran, Iran \\ Springer}


4. Process integration. It is related to a high level of integration between partners within the supply chain and enables collaborative working methods such as joint product design. Therefore, the partners within the supply chain network will be able to improve a variety of products and deal with uncertainty.

Supply chain network design (SCND) decisions, as the most important strategic level decisions in supply chain management, are concerned with complex interrelationships between various tiers, such as suppliers, plants, distribution centers, and customer zones as well as determining the number, location, and capacity of facilities to meet customer needs effectively. Supply chain management integrates interrelationships between various entities through creating alliance, such as information system integration and process integration, between entities to improve response to customers in various aspects such as, higher product variety and quality, lower costs, and faster responses. One of the vital challenges for organizations in today's competitive markets is the need to respond to customer needs, which are very volatile and can occur in volume and in a variety of customer needs (Amir 2011). Agility with its various contexts is the most popular strategy that enables organizations to confront unstable and highly volatile customer demands. Since the SCND is the most important strategic level decision that affects the overall performance of supply chain, it is necessary to consider agility concepts such as response to customers in maximum allowable time, direct shipment, alliance (information and process integration) between entities in different echelons, discount to achieve competitive supply chain, outsourcing, using different transportation modes to achieve flexibility, and safety stock to improve responsiveness. It is evident that considering agility concepts in SCND plays an incredible role in agility of the overall supply chain. As yet, many researchers have tried to show the most important factors in agile supply chain management theoretically, and this context has been omitted in the mathematical modeling area especially in the supply chain network design area.

In this paper, to overcome literature gaps in agile supply chain network design, we present a mixed-integer linear programming (MILP) model that is able to consider agility concepts such as response to customers in maximum allowable time, direct shipments besides the traditional shipments, alliance between opened facilities in different tiers, safety stock, different transportation modes, discount, and outsourcing besides the traditional features of the SCND area. The reminder of this paper is organized as follows. The related works are reviewed. 'Description and formulation of the proposed model' includes the description and formulation of the proposed model. The numerical results are reported in 'Results and discussion'. Finally, 'Conclusions' concludes this paper and offers some directions for further research.

\section{Results and discussion}

\section{Computational results}

In order to evaluate the performance of the presented model for designing agile supply chain network, two test problems are randomly generated according to the information specified in Table 1 inspired from literature. Interested readers can reach the detailed data set for the two test problems from the authors. Customer service level is considered to be $75 \%$ (i.e., $\mathrm{csl}=0.75$ ) in the two test problems. It should be mentioned that opening and closing a facility is a strategic decision, and a timeconsuming and costly process. Therefore, changing facility location is impossible in the short run. On the other hand, determining the quantities of flow between the facilities of the network as a tactical decision is more flexible to change in the short run (Pishvaee et al. 2009). Therefore, strategic decisions (binary variables) should be determined independently from realizations, whereas tactical decisions can be changed and updated during the realizations.

The proposed model is solved by ILOG CPLEX 10.1 optimization software on a Pentium dual-core $2.60-\mathrm{GHz}$

\section{Table 1 Data generation}

\begin{tabular}{|c|c|}
\hline Parameter & Value \\
\hline$\overline{d_{k}}$ & $\sim$ Unif $(100,200)$ unit \\
\hline$\overline{f_{i}}$ & $\sim$ Unif $(1,700,000,4,000,000) \$$ \\
\hline$\overline{g_{j}^{r}}$ & $\sim$ Unif $(1,600,000,3,000,000) \$$ \\
\hline $\mathrm{pr}_{i}$ & $\sim$ Unif $(120,150) \$$ \\
\hline$\overline{m h_{j}}$ & $\sim$ Unif $(60,75) \$$ \\
\hline $\mathrm{CS}_{i}$ & $\sim$ Unif $(90,170) \$$ \\
\hline$\overline{\mathrm{Ml}_{j}}$ & $\sim$ Unif $(80,100) \$$ \\
\hline $\mathrm{MV}_{i}$ & Unif $(90,110)$ unit \\
\hline $\mathrm{DP}_{i}$ & $\sim$ Unif $(400,550)$ unit \\
\hline $\mathrm{CD}_{i}$ & $\sim$ Unif $(10,500,14,500) \$$ \\
\hline$a_{k}$ & $\sim$ Unif $(4,000,6,000) \$$ \\
\hline$a_{i j n}$ & $\sim$ Unif $(40,60) \$$ \\
\hline$\overline{b_{j k n}}$ & $\sim$ Unif $(40,60) \$$ \\
\hline$e_{i k n}$ & $\sim$ Unif $(90,130) \$$ \\
\hline $\operatorname{ta}_{i k n}$ & $\sim$ Unif(10,16) day \\
\hline $\mathrm{tc}_{j k n}$ & $\sim$ Unif(6,12) day \\
\hline $\mathrm{te}_{k}$ & $\sim$ Unif(10,12) day \\
\hline $\mathrm{caw}_{i}^{r}$ & $\sim$ Unif $(2,000,5,000)$ unit \\
\hline $\mathrm{cay}_{j}^{r}$ & $\sim$ Unif $(2,000,3,500)$ unit \\
\hline $\mathrm{CPA} 1_{i m}$ & $\sim$ Unif $(50,000,60,000) \$$ \\
\hline $\mathrm{CPA} 2_{j c}$ & $\sim$ Unif $(30000,35,000) \$$ \\
\hline $\mathrm{CPA}_{i j}$ & $\sim$ Unif $(60,000,70,000) \$$ \\
\hline
\end{tabular}

Unif, uniform distribution. 
Table 2 Computational results and complexity of presented models

\begin{tabular}{lllll}
\hline $\begin{array}{l}\text { Problem size } \\
|\mathbf{K}| *||^{*}|\mathbf{J}| * \mathbf{N}|*| \mathbf{R} \mid\end{array}$ & O.F.V & Constraints & Variables & $\begin{array}{l}\text { Run } \\
\text { time(s) }\end{array}$ \\
\hline $10^{*} 5^{*} 83^{*} 2$ & $16,015,980$ & 813 & 690 & 0.8 \\
$15^{*} 10^{*} 10 * 3 * 2$ & $22,917,570$ & 1,578 & 1,861 & 29 \\
\hline
\end{tabular}

O.F.V, objective function value.

computer with 4 GB RAM. To reduce the complexity of deterministic model, we relax the decision binary variables $\mathrm{PA} 1_{i m}, \mathrm{PA} 2_{j c}$, and $\mathrm{PA}_{i j}$ as continuous variables. It should be noted that minimization of the objective function and binary variables $W_{i}^{r}$ and $Y_{j}^{r}$ in constraints (8) to (14) assures that the relaxed variables are set equal to 0 or 1 .

Acquired results illustrated in Table 2 show that by increasing the size of the problem in question, objective function value (O.F.V) and complexity of the discussed problems increase. Table 3 demonstrates the share of different objective function components for the proposed model in details. As it is illustrated in Table 3, the fixed costs for opening facilities have the largest share in the objective function value for both models. Therefore, determining the number and location of facilities in each stage of the SCND process is the most important strategic decision which has effects on the overall performance of the SCN. Moreover, the total costs of production, outsourcing, inventory, and transportation are significant in the objective function. This is because the demand of customers must be satisfied based on predefined customer service level representing upstream of the supply chain management. Additionally, the share of outsourcing cost is lesser than production cost in the objective function value. It could be explained by the limitation on the majority of the products that could be outsourced (see constraint 8 in 'Description and formulation of the proposed model').

As described in previous sections, alliance between facilities in the supply chain network plays an important role in integration and success of the agile supply chain. The model pays alliance cost to improve information and process integration. In addition, although discount issue can improve competitiveness of the agile supply chain, its amount should be balanced with other costs.

As depicted in Figure 1, sensitivity analysis on demand of customers shows that the proposed model is sensitive to demand of customers. This observation can be explained by the demand's effect on the overall supply chain network. In other words, the configuration of the supply chain network is constructed according to customer demands.

The considered agile supply chain network in this paper has a general structure that is able to support the agility concepts besides the traditional features of the SCND area and, therefore, could be applied to different kinds of industries with lead time restriction such as food industries and semiconductor industries. It can be concluded from the acquired results that the proposed model can be utilized as a power tool in practical cases with less shortage and high degree of responsiveness.

\section{Conclusions}

In this paper, we proposed a supply chain network design problem for a new market opportunity in an agile manufacturing system. The proposed agile SCND model is able to integrate production, outsourcing, discount, flexibility, and distribution activities by considering the most important factors of the agile supply chain. The experimental results show the efficiency of the proposed model in an agile supply chain network design. Also, it can be concluded from the obtained results that the locations of facilities in the supply chain network design are a strategic decision, and therefore, integration of facility location decisions with other decisions such as outsourcing, inventory control, production, etc. can improve supply chain performance and responsiveness.

Many possible future research avenues can be defined for future research directions. For example, addressing multi-product, multi-period agile supply chain network design under different kinds of operational and disruption risks is an attractive research direction with significant practical relevance. Moreover, time complexity is not addressed in this paper; however, this issue might be important in large-sized problems that the commercial solvers failed to solve; therefore, developing efficient exact, or heuristic solution methods can be interesting in this area.

\section{Methods}

\section{Related works}

In this section, we concisely review some SCND model developed recently. Melo et al. (2009) presented a general review on supply chain network design to identify basic features that such models must capture to support

Table 3 Share of different components of objective functions

\begin{tabular}{lllllllll}
\hline $\begin{array}{l}\text { Problem size } \\
|\mathbf{K}|^{*}||^{*}|\mathbf{J}|^{*}\left|\mathbf{N} \mathbf{*}^{*}\right| \mathbf{R} \mid\end{array}$ & $\begin{array}{l}\text { Fixed } \\
\text { costs }\end{array}$ & $\begin{array}{l}\text { Production } \\
\text { costs }\end{array}$ & $\begin{array}{l}\text { Outsourcing } \\
\text { costs }\end{array}$ & $\begin{array}{l}\text { Inventory } \\
\text { costs }\end{array}$ & $\begin{array}{l}\text { Transportation } \\
\text { costs }\end{array}$ & $\begin{array}{l}\text { Alliance } \\
\text { costs }\end{array}$ & $\begin{array}{l}\text { Shortage } \\
\text { costs }\end{array}$ & $\begin{array}{l}\text { Discount } \\
\text { amount }\end{array}$ \\
\hline $10^{*} 5^{*} 8^{*} 3^{*} 2$ & $13,403,300$ & $1,220,666$ & 30,400 & 12,130 & 801,739 & 583,819 & 0 & 36,076 \\
$15^{*} 10^{*} 10^{*} 3^{*} 2$ & $19,142,810$ & $1,764,269$ & 30,700 & 18,269 & $1,145,611$ & 840,050 & 12,168 & 36,309 \\
\hline
\end{tabular}




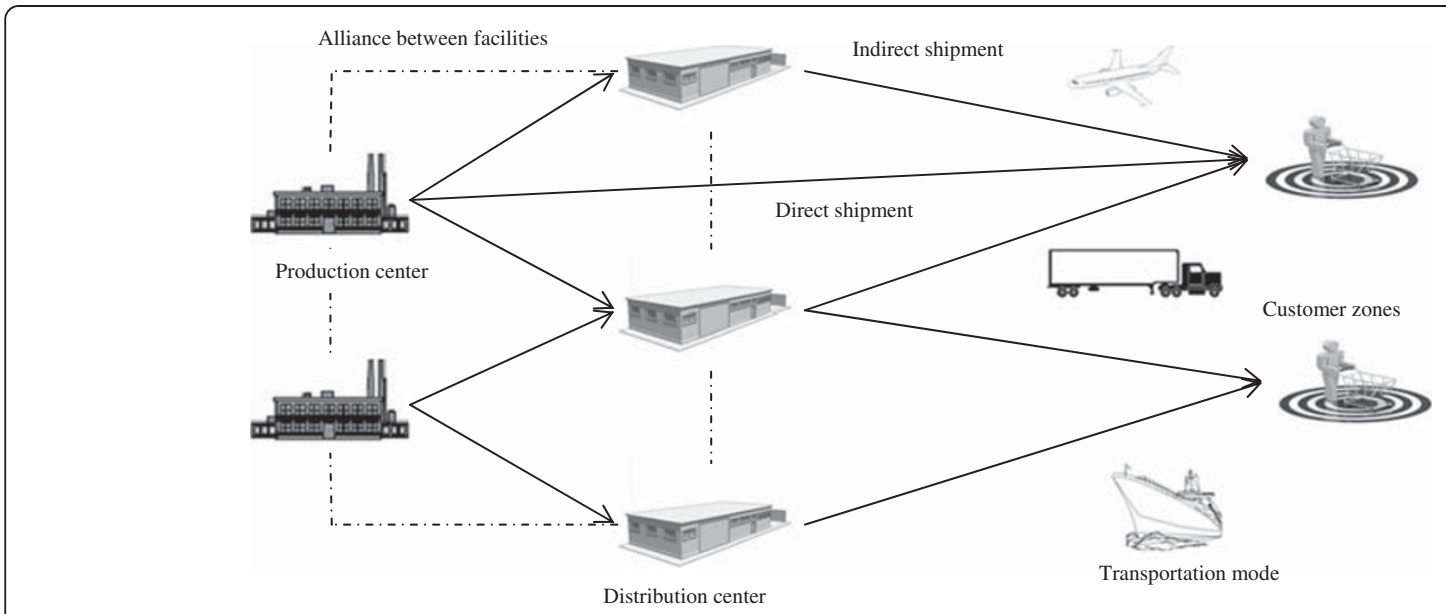

Figure 1 Objective function vs. demand mean.

decision making involved in strategic supply chain planning and to support a variety of future research directions. Other interesting reviews in this field can be found in Dullaert et al. (2007) and Snyder (2006). Most of the presented models in the literature focus on minimization of total costs and ignore other objectives such as responsiveness and flexibility, which are effective in the success of supply chain management. Zanjirani Farahani et al. (2010) gave a comprehensive review on multi-criteria facility location problems in the SCND. Their study shows that only approximately $8 \%$ of presented models have considered responsiveness as a determining factor in SCND. You and Grossmann (2008) developed a responsive bi-objective MINLP model by considering demand uncertainty and economic criterion. Their model was able to determine the safety stock levels to confront uncertainty. They used $\epsilon$-constraint method to produce Pareto front. Rajabalipour Cheshmehgaz et al. (2011) presented a multi-objective, multistage, flexible model to design logistics network with the aim of minimizing response time and cost criteria. The efficient multi-objective evolutionary algorithm based on genetic algorithm (GA) was proposed. Ross and Jayaraman (2008) developed a MILP model to determine the location of the cross-docks in the SCND. Also, they utilized simulated annealing and Tabu search to solve the presented model. Amiri (2006) presented a MILP model to coordinate production and distribution activities. Additionally, the presented model was able to determine the optimum number, location, and capacity of facilities that should be opened. Altiparmak et al. (2006) developed a SCND model in a practical case and then proposed a GA by using priority-based encoding to escape from infeasible solutions. Thanh et al. (2008) proposed a dynamic MILP model for the facility location in the SCND. The proposed model includes strategic and tactical decisions.
As yet, among the numerous SCND models, which are presented to design SCN in an efficient way and improve supply chain management, agility as a winning factor in today's turbulent markets has been omitted. However, in recent years, some studies have tried to consider the agility concepts in SCND. Bachlaus et al. (2008) presented an integrated multi-objective MILP model to integrate production, distribution, and supply chain activities as strategic decisions considering agility as a key design criterion. They defined agility index in three levels including low, medium, and high for each facility, which should be satisfied in constraints. Additionally, they used flexibility as available capacity of each facility, which should be maximized in objective function. Pan and Nagi (2010) developed a robust optimization approach to deal with demand uncertainty in supply chain network in agile manufacturing. The presented model was able to consider alliance costs, which is one of the important factors of agile supply chain, between opened facilities. They proposed an efficient heuristic based on a k-shortest path algorithm to solve the presented model in large scales. However, their model doesn't cover distribution centers and delivery time to customer as well as one facility which should be determined in any echelon of supply chain network, and the robust optimization is based on scenarios. Hasani et al. (2011) presented a closed-loop supply chain network for perishable goods under uncertainty of demand and purchasing costs. Agility can be seen as handling products in their lifetime period. They used a bounded-box robust optimization approach to confront uncertainty in their model and solved it using LINGO.

\section{Description and formulation of the proposed model}

The concerned agile supply chain network in this paper is a multi-echelon and direct acyclic network, which 
integrates the production, outsourcing, flexibility, discount, safety stock, shortage, and distribution activities. In each echelon, there are some candidate facilities which should be determined to design the network in question. The discussed echelons are linked together with a forward shipment of products and backward flow of information in a pull system. As it is shown in Figure 2, the finished products manufactured in plants and semifinished products, which have been outsourced, are shipped to distribution centers or directly shipped to customer zones after processing in plants. The direct shipment of products includes shipping the products from production centers to the customer zones directly, while indirect shipment of products includes the shipping of goods from production centers to the distribution centers and then to the customer zones. Since direct shipment of products has higher costs with respect to indirect shipment, and there are budget limitations in this process, we assume that only a certain amount of products can be directly shipped. All direct and indirect shipments are performed in several transportation modes including land, sea, and/or air. Using different transportation modes improves the flexibility and responsiveness of the supply chain network in the sense that when utilizing a special transportation mode is not possible, the others could be efficiently used. Also, in critical conditions, the products could be delivered in maximum allowable time by using faster transportation modes to improve responsiveness. Some of the finished products in production centers shipped to distribution centers are stored, and the rest are shipped to customer zones according to customer needs. It should be noted that agile supply chains try to satisfy all customer demands; however, some customer needs may be not satisfied in the real world. Therefore, shortage can occur based on predefined customer service level.

To achieve flexibility and deal with disruption risks, the plants can perform outsourcing and use different transportation modes to deliver new products to customers. It is worthy to note that because of the

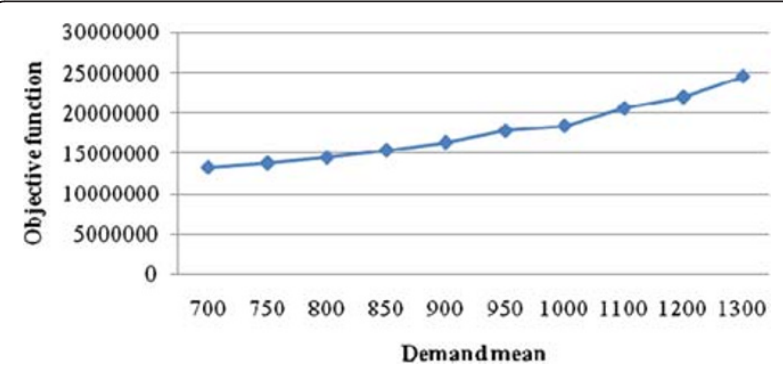

Figure 2 Structure of the concerned agile supply chain network. keeping independency, the maximum amount of outsourced products should be restricted so that the supply chain network will be able to respond to customer needs effectively when some of the suppliers are disrupted. Disruption of suppliers could occur because of natural disaster or other issues such as terrorist attacks and labors strike. As mentioned in previous sections, alliance between facilities is a key factor to improve agility of the supply chain. Creating alliance between opened facilities, selected to form the agile supply chain network, enables facilities to share their information, improve organizational educations, leverage organizational skills, and participate in new product development. Therefore, we assume that the supply chain network pays a certain cost to create alliance between opened facilities in different echelons. As regards delivery time to customers playing an incredible role in improving responsiveness to customers, we assume that all costumer demands should be met in their expected times. Another important issue in SCND is determining the capacity of facilities which should be opened. Most of the previously presented models consider fixed capacities for facilities, whereas determining the capacity of facilities is often difficult in practice (Wang et al. 2009). Therefore, it is assumed that the capacity level of facilities is determined as a decision variable to avoid additional and useless costs.

The following notation is used in the formulation of the proposed model.

Indices

$I, M$ Index of candidate locations for plants $(i, m=1, \ldots, I)$

$J, C$ Index of candidate locations for distribution centers $(j, c=1, \ldots, J)$

$K$ Index of fixed locations of customers $(k=1, \ldots, K)$

$N$ Index of transportation modes $(n=1, \ldots, N)$

$R$ Index of capacity levels $(r=1, \ldots, R)$

\section{Parameters}

$d_{\mathrm{k}}$ Demand of customer $k$

$f_{i}$ Fixed cost of opening plant $i$ with capacity level $r$

$g_{j}^{r}$ Fixed cost of opening distribution center $j$ with capacity level $r$

$\operatorname{pr}_{i}$ Production cost per unit of products at plant $i$

CPA $1_{i m}$ Process and information (alliance) integration cost between plants $i$ and $m$

$\mathrm{CPA} 2_{j c}$ Process and information integration cost between distribution centers $j$ and $c$

$\mathrm{CPA}_{i j}$ Process and information integration cost between plants $i$ and distribution center $j$

$\mathrm{CD}_{i}$ Discount amount by plant $i$ to customers 
$\alpha_{k}$ Penalty cost per unit of unsatisfied demand of customer $k$

$\mathrm{mh}_{j}$ Material handling and inventory cost per unit of products at distribution center $j$

$\mathrm{oc}_{i}$ Outsourcing cost per unit of products at plant $i$

$a_{i j n}$ Unit transportation cost from plant $i$ to distribution center $j$ by mode $n$ for product $p$

$b_{j k n}$ Transportation cost per unit of products from distribution center $j$ to customer $k$ by mode $n$

$e_{i k n}$ Transportation cost per unit of products from plant $i$ to customer $k$ by mode $n$

$\mathrm{ta}_{i k n}$ Delivery time from plant $i$ to customer $k$ by mode $n$

$\mathrm{tc}_{j k n}$ Delivery time from distribution center $j$ to customer $k$

te $_{k}$ Expected delivery time of customer $k$

$\mathrm{MI}_{j}$ Minimum inventory which should be held in distribution center $j$

$\mathrm{MV}_{i}$ Maximum amount of products which can be outsourced in plant $i$

$\mathrm{DP}_{i}$ Minimum amount required that plant $i$ offers discount to customers

csl Percentage of predetermined customer service level

$\operatorname{caw}_{i}^{r}$ Capacity with level $r$ for plant $i$

cay $_{j}^{r}$ Capacity with level $r$ for distribution center $j$

Decision variables

$\mathrm{xu}_{i}$ Quantity of products produced at plant $i$

$\mathrm{In}_{j}$ Quantity of products held at distribution center $j$

$v_{i}$ Quantity of products outsourced at plant $i$

$\delta_{k}$ Quantity of unsatisfied demand of customer $k$

$x_{i j n}$ Quantity of products shipped from plant $i$ to distribution center $j$ by mode $n$

$Q_{j k n}$ Quantity of products shipped from distribution center $j$ to customer $k$ by mode $n$

$L_{i k n}$ Quantity of products shipped directly from plant $i$ to customer $k$ by mode $n$

$W_{i}^{r} 1$ if plant $i$ with capacity level $r$ is opened; otherwise, 0

$y_{j}^{r} 1$ if distribution center $j$ with capacity level $r$ is opened; otherwise, 0

PA $1_{i m} 1$ if process and information integration is performed between plant $i$ and plant $m$; otherwise, 0

$\mathrm{PA} 2_{j c} 1$ if process and information integration is performed between distribution center $j$ and distribution center $c$; otherwise, 0

$\mathrm{PA}_{i j} 1$ if process and information integration is performed between plant $i$ and distribution center $j$; otherwise, 0

$\lambda_{i} 1$ if plant $i$ gives discount to customers, otherwise, 0

$$
\begin{aligned}
\min & \sum_{i} \sum_{r} f_{i}^{r} w_{i}^{r}+\sum_{j} \sum_{r} g_{j}^{r} y_{j}^{r}+\sum_{i}\left(\mathrm{pr}_{i} \mathrm{xu}_{i}+\mathrm{oc}_{i} v_{i}\right) \\
& +\sum_{j} \operatorname{mh}_{j} \mathrm{In}_{j}+\sum_{i} \sum_{j} \sum_{n} a_{i j n} x_{i j n} \\
& +\sum_{j} \sum_{k} \sum_{n} b_{j k n} Q_{j k n}+\sum_{i} \sum_{k} \sum_{n} e_{i k n} L_{i k n} \\
& +\sum_{i} \sum_{m \neq i} \frac{1}{2} \mathrm{CPA}_{i m} \mathrm{PA}_{i m}+\sum_{j} \sum_{c \neq j} \frac{1}{2} \mathrm{CPA}_{j c} \mathrm{PA} 2_{j c} \\
& +\sum_{i} \sum_{j} \mathrm{CPA}_{i j} \mathrm{PA}_{i j}+\sum_{k} \alpha_{k} \delta_{k}-\sum_{i} \mathrm{CD}_{i} \lambda_{i} \text { S.t. }
\end{aligned}
$$

$\sum_{i} \sum_{n} L_{i k n}+\sum_{j} \sum_{n} Q_{j k n}+\delta_{k} \geq d_{k} \forall k$

$\delta_{k} \leq(1-\operatorname{csl}) d_{k} \forall k$

$\lambda_{i} \leq \frac{d_{k}}{D P_{i}} \forall i, k$

$\sum_{i} \sum_{j} \sum_{n} x_{i j n}+\sum_{i} \sum_{k} \sum_{n} L_{i k n}=\sum_{i}\left(\mathrm{xu}_{i}+v_{i}\right)$

$\sum_{i} \sum_{n} x_{i j n}=\sum_{k} \sum_{n} Q_{j k n}+\operatorname{In}_{j} \forall j$

$\operatorname{In}_{j} \geq \sum_{r} y_{j}^{r} \mathrm{MI}_{j} \forall j$

$v_{i} \leq \sum_{r} w_{i}^{r} \mathrm{MV}_{i} \forall i$

$\mathrm{PA}_{i m} \leq \sum_{r} w_{i}^{r} \forall i, m \neq i$

$\mathrm{PA}_{i m} \geq \sum_{r} w_{i}^{r}+\sum_{r} w_{m}^{r}-1 \forall i, m \neq i$

$\mathrm{PA} 2_{j c} \leq \sum_{r} y_{j}^{r} \forall j, c \neq j$

$\mathrm{PA} 2_{j c} \geq \sum_{r} y_{j}^{r}+\sum_{r} y_{c}^{r}-1 \forall j, c \neq j$

$\mathrm{PA}_{i j} \leq \sum_{r} w_{i}^{r} \forall i, j$

$\mathrm{PA}_{i j} \leq \sum_{r} y_{j}^{r} \forall i, j$

$\mathrm{PA}_{i j} \geq \sum_{r} w_{i}^{r}+\sum_{r} y_{j}^{r}-1 \forall i, j$

$L_{i k n} \mathrm{ta}_{i k n} \leq L_{i k n} \mathrm{te}_{k} \forall i, k, n$

$Q_{j k n} \mathrm{tc}_{j k n} \leq Q_{j k n} \mathrm{te}_{k} \forall j, k, n$

$\lambda_{i} \leq \sum_{r} w_{i}^{r} \forall i$

$\mathrm{xu}_{i} \leq \sum_{r} w_{i}^{r} \operatorname{caw}_{i}^{r} \forall i$ 


$$
\begin{aligned}
& \sum_{i} \sum_{n} x_{i j n} \leq \sum_{r} y_{j}^{r} \mathrm{cay}_{j}^{r} \forall j \\
& \sum_{j} \sum_{n} x_{i j n}+\sum_{k} \sum_{n} L_{i k n} \leq \sum_{r} w_{i}^{r} U \forall i \\
& \mathrm{xu}_{i} \geq \mathrm{LB}_{i} \sum_{r} w_{i}^{r} \mathrm{caw}_{i}^{r} \forall i \\
& \sum_{i} \sum_{k} \sum_{n} L_{i k n} \leq \mathrm{UB} \\
& \sum_{r} w_{i}^{r} \leq 1 \forall i \\
& \sum_{r} y_{j}^{r} \leq 1 \forall j \\
& \mathrm{xu}_{i}, \mathrm{In}_{j}, v_{i}, x_{i j n}, L_{i k n}, Q_{j k n}, \delta_{k} \geq 0 \forall i, j, k, n \\
& w_{i}^{r}, y_{j}^{r}, \lambda_{i}, \mathrm{PA}_{i m}, \mathrm{PA}_{j c}, \mathrm{PA}_{i j} \in\{0,1\} \forall i, j, r, m, c
\end{aligned}
$$

Objective function (1), which minimizes the total costs, includes fixed opening costs, production cost, outsourcing cost, inventory holding cost, transportation and processing costs, alliance costs between opened facilities, and shortage costs as well as the amount of discount, is maximized to improve competitiveness of the agile supply chain network. Coefficient $(1 / 2)$ is considered to avoid recalculation of alliance costs between opened facilities in the same echelon. Constraint (2) ensures that all demands of customers are not satisfied, and shortage is possible. Constraint (3) imposes the maximum allowable shortage based on predefined customer service level. Constraint (4) is inequality for decision making on giving discount to customers. It should be noted that since the discount amount is maximized in the objective function to improve the competency of supply chain network, the binary variable $\lambda_{i}$ gives the value 1 when the customers purchase the certain amount of products specified to give discount (i.e., $\mathrm{DP}_{i}$ ). Constraints (5) and (6) are the flow balances at the plants and warehouses, respectively. Constraint (7) imposes the minimum inventory which should be stored as safety stocks in opened warehouses. Constraint (8) assures that the amount of outsourced products doesn't exceed a certain amount to assure independency. Constraint (9) expresses that to create alliance between the production centers of the agile supply chain network, the production centers should be determined among the candidate locations with specified capacities in advance. Constraint (10) quarantines the creation of alliance between opened production centers in the first echelon. For example, assume a production center with capacity level 2 is established in location 3 (i.e., $w$ $(3,2)=1)$, and another production center with capacity level 1 is established in location 4 (i.e., $w(4,1)=1$ ), so the alliance between these production centers will be created (i.e., PA1 $(3,4) \geq 1+1-1)$. Note that the PA1 is a binary variable and so will be equal to 1 . Constraints (11) and (12) are the same as constraints (9) and (10) to create alliance between opened distribution centers in the second echelon. Constraints (13) and (14) express that to create alliance between production and distribution centers in different echelons, they should be selected for establishing among the candidate locations in advance. Constraint (15) ensures that when the production center and distribution center are established in different echelons, the alliance will be created between them. Constraints (16) and (17) ensure that all the products are delivered to customers in the maximum allowable delivery time. Restriction (18) expresses that only opened plants are allowed to give discount to customers. Constraints (19) and (20) are capacity constraints in any facility. Constraint (21) ensures that only opened plants can send products to warehouses and customer centers. Constraint (22) expresses the utilization of lower-bound percentage of the capacity of opened plants. Constraint (23) expresses the limitation on the total number of products directly sent to customers. Constraints (24) and (25) ensure that any facility can be opened, at most, in one of the capacity levels. Finally, constraints (26) and (27) enforce the binary and non-negativity restrictions on corresponding decision variables.

Competing interests

The authors declare that they have no competing interests.

\section{Authors' contributions}

RB proposed the mathematical model and solved it. JR managed the study and was responsible for integrating and revising the manuscript. RG participated in the design of the study.

\section{Acknowledgments}

We would like to thank from anonymous referees for their constructive and valuable comments that improved the contents of the paper substantially. All authors read and approved the final manuscript.

Received: 10 March 2012 Accepted: 12 August 2012

Published: 30 August 2012

\section{References}

Altiparmak F, Gen M, Lin L, Paksoy T (2006) A genetic algorithm approach for multi-objective optimization of supply chain networks. Computlnd Eng 51:197-216

Amiri A (2006) Designing a distribution network in a supply chain system: formulation and efficient solution procedure. Eur J Oper Res 171:567-576

Amir F (2011) Significance of lean, agile and leagile decoupling point in supply chain management. Journal of Economics and Behavioral Studies 3(5):287-295

Bachlaus M, Mayank KP, Chetan M, Ravi S, Tiwari MK (2008) Designing an integrated multi-echelon agile supply chain network: a hybrid taguchiparticle swarm optimization approach. J Intell Manuf 19:747-761

Christopher M, Lowson R, Peck H (2004) Creating agile supply chains in the fashion industry. International Journal of Retail \& Distribution Management 32(8):367-376

Dullaert W, Braysy O, Goetschalckx M, Raa B (2007) Supply chain (re)design: support for managerial and policy decisions. Eur J Transp Infrastruct Res 7(2):73-91 
Hasani A, Zegordi SH, Nikbakhsh H (2011) Robust closed-loop supply chain network design for perishable goods in agile manufacturing under uncertainty. Int J Prod Res. doi:10.1080/00207543.2011.625051

Harrison A, Hoek R, Christopher M (1999) Creating the Agile Supply Chain. Institute of Logistic \&Transport, London

Lin CT, Chiu H, Chu PY (2006) Agility index in the supply chain. Int J Prod Econ 100(2):285-299

Mason-Jones R, Naylor JB, Towill DR (2000) Engineering the leagile supply chain. International Journal of Agile Manufacturing Systems 2(1):54-61

Melo MT, Nickel S, Saldanha-da-Gama F (2009) Facility location and supply chain management: a review. Eur J Oper Res 196:401-412

Pan F, Nagi R (2010) Robust supply chain design under uncertain demand in agile manufacturing. Comput Oper Res 37:668-683

Pishvaee MS, Jolai F, Razmi J (2009) A stochastic optimization model for integrated forward/reverse supply chain network design. J Manuf Syst 28:107-114

Rajabalipour Cheshmehgaz H, Ishak Desa M, Wibowo A (2011) A flexible three-level logistic network design considering cost and time criteria with a multi-objective evolutionary algorithm. J Intell Manuf. doi:10.1007/s10845-011-0584-7

Ross A, Jayaraman V (2008) An evaluation of new heuristics for the location of cross-docks distribution centers in supply chain network design. Comput Ind Eng 55:64-79. doi:10.1016/j.cie.2007.12.001

Snyder LV (2006) Facility location under uncertainty: a review. IIE Trans 38(7):547-564

Thanh PN, Bostel N, Peton O (2008) A dynamic model for facility location in the design of complex supply chains. Int J Prod Econ 113:678-693

Wang S, Watada J, Pedrycz W (2009) Value-at-risk-based multi-stage fuzzy facility location problems. IEEE transactions on industrial informatics 5:465-482

You F, Grossmann IE (2008) Design of responsive supply chains under demand uncertainty. Comput Chem Eng 32:3090-3111

Zanjirani Farahani R, Steadie Seifi M, Asgari N (2010) Multiple criteria facility location problems: a survey. Appl Math Model 34:1689-1709

doi:10.1186/2251-712X-8-19

Cite this article as: Babazadeh et al:: Supply chain network design problem for a new market opportunity in an agile manufacturing system. Journal of Industrial Engineering International 2012 8:19.

\section{Submit your manuscript to a SpringerOpen ${ }^{\circ}$ journal and benefit from:}

- Convenient online submission

- Rigorous peer review

- Immediate publication on acceptance

- Open access: articles freely available online

- High visibility within the field

- Retaining the copyright to your article

Submit your next manuscript at $>$ springeropen.com 